\title{
Patient perceptions of multiple sclerosis and its treatment
}

\author{
This article was published in the following Dove Press journal: \\ Patient Preference and Adherence \\ 3 April 2012 \\ Number of times this article has been viewed
}

\author{
Jérôme de Seze' \\ Florent Borgel ${ }^{2}$ \\ Frédérique Brudon ${ }^{3}$ \\ 'Department of Neurology CHRU \\ de Strasbourg, Strasbourg, ${ }^{2}$ Medical \\ Center, Grenoble, ${ }^{3}$ Clinique du Tonkin, \\ Villeurbanne, France
}

Background: In order to improve the treatment outcome in multiple sclerosis, it is important to document the factors that influence adherence to therapy. The purpose of this study was to determine patient perceptions and awareness of multiple sclerosis and its treatment, treatment adherence, and impact on quality of life and daily living.

Methods: This was a cross-sectional observational study performed in France. Each participating neurologist included the first three patients with relapsing-remitting multiple sclerosis who consulted after the start of the study. Data on clinical features were collected from a physician questionnaire and on disease and treatment perception and on quality of life from a patient autoquestionnaire.

Results: A total of 175 neurologists entered 202 patients in the study. The mean duration of disease was $8.0 \pm 7.0$ years, and immunomodulatory treatment had been administered for a mean duration of $3.0 \pm 2.0$ years. A total of 166 patients $(82.2 \%)$ were treated with interferon- $\beta$ preparations and 36 patients $(17.8 \%)$ with glatiramer acetate. Eighty-five patients $(42.1 \%)$ reported missing their injections from time to time and 36 patients $(17.8 \%)$ reported "drug holidays". The most frequently given reason for nonadherence was forgetfulness ( $38.7 \%$ of cases). Eighty-six patients $(42.6 \%)$ and 70 patients (34.7\%) claimed to be well informed about their disease and treatment, respectively. Adherence was significantly higher in well informed patients $(P=0.035)$. The majority of patients (176 patients, $87.1 \%)$ intended continuing their current treatment and $49.5 \%$ considered that their current treatment might reduce relapses. The most frequently reported side effect was muscle pain (124 patients, $61.4 \%$ ).

Conclusion: Patient understanding of treatment for disease enhances treatment adherence. Greater patient involvement in disease management requires better communication between physicians and their patients.

Keywords: multiple sclerosis, patient adherence, quality of life

\section{Introduction}

Multiple sclerosis is a common, chronic inflammatory disease of the central nervous system, which most frequently appears in early adulthood and is more frequent in women than in men. Given that multiple sclerosis usually affects people in the most active and productive phase of their lives, and since the frequency and severity of attacks are largely unpredictable, the impact of the disease on activities of daily living, functioning, and quality of life can be important. ${ }^{1-3}$

Disease management in multiple sclerosis involves treatment of acute relapses, use of disease-modifying treatments to prevent relapses, and symptom management. Disease-modifying treatments, of which four are currently licensed for
Correspondence: Jérôme de Seze Département de Neurologie, Hôpital Civil I, place de l'hôpital, BP 426, 6709I Strasbourg Cedex, France

Tel +33388 I 5023

$\mathrm{Fax}+33388115153$

Email jerome.de.seze@chru-strasbourg.fr 
the first-line treatment of relapsing-remitting multiple sclerosis (three interferon- $\beta$ preparations and glatiramer acetate), have been demonstrated in large randomized clinical trials to reduce relapse rates, improve magnetic resonance imaging markers of disease activity, and in some cases to slow disease progression. ${ }^{4-7}$ These treatments, which are all administered by injection, need to be taken over the long term, perhaps lifelong, because interruption of treatment leads to recrudescence of disease activity. ${ }^{8}$ However, many previous studies have demonstrated that adherence to injectable immunomodulatory therapies is poor. ${ }^{9}$ For example, in a cohort of 308 patients in Germany followed prospectively for 2 years after treatment initiation, ${ }^{10} 25$ patients $(8.1 \%)$ discontinued in the first 6 months and a further $68(22.1 \%)$ had stopped their treatment at the end of 2 years of follow-up..$^{10}$ In an Irish cohort, $28 \%$ of patients starting on interferon- $\beta$ had discontinued by 5 years. ${ }^{11}$ Even higher discontinuation rates have been reported elsewhere, ie, $41.1 \%$ of patients treated with interferon- $\beta 1 \mathrm{~b}$ after 3 years in a large prospective Italian cohort ${ }^{12}$ and $38.9 \%$ after 3 years in a retrospective chart review in Canada. ${ }^{13}$

Strategies to improve treatment outcome in multiple sclerosis thus need to ensure optimal adherence to therapy. ${ }^{14,15}$ In order to do this, it is important to understand the relative importance of the different factors that influence adherence. To this end, we have performed a survey in order to investigate patient-reported perceptions of disease and treatment. The principal objectives of this study were to describe the perceived benefits and limitations of current immunomodulatory treatments for multiple sclerosis, treatment adherence, impact on quality of life and daily living, and treatment expectations and needs.

\section{Methods}

\section{Study design}

This was a cross-sectional observational survey conducted in France between April 24 and May 31, 2006. The survey was implemented by TNS SOFRES, an international polling institute. A letter was sent to the 1118 neurologists practicing in France inviting them to participate in the survey, of whom 175 (15.7\%) agreed to take part. It should be noted that French legislation on medical studies and surveys requires that the protocol be proposed to all specialists in the country, regardless of whether they see the target patient group or not. In the case of multiple sclerosis, almost all non-institutionalized patients are managed in a national network of 44 centers (Observatoire Français de la Sclérose en Plaques; http://www.edmus.org/en/proj/observatoire.html) involving around 400 neurologists.

\section{Population}

Each participating neurologist was expected to include the first three patients with relapsing-remitting multiple sclerosis who consulted after the start of the study and who agreed to take part in the survey. Inclusion criteria were a diagnosis of relapsing-remitting multiple sclerosis, an Expanded Disability Status Scale score (EDSS) score $\leq 5.5$, and prescription of an immunomodulatory treatment for at least 3 months.

\section{Data collection}

Data were collected from a physician questionnaire completed during the consultation and from a patient auto questionnaire which the neurologist gave to the patient to be completed at home and sent directly to the company responsible for analyzing the data in a prepaid envelope. Both questionnaires were designed specifically for this study.

The physician questionnaire collected data on the age, gender, and clinical features of the patient, and on the treatment used. The number of relapses in the previous 2 years, the last available EDSS score, and the time since diagnosis were documented. The patient auto questionnaire collected information on sociodemographics, disease and treatment perceptions, information about multiple sclerosis, involvement in treatment decisions, adherence, side effects, and impact of treatment on quality of life as well as on patient involvement in managing the disease and its treatment. Side effects were identified on a 13-item checklist (11 identified side effects, "other side effects", and "no side effects") relating to side effects that the patient considered to be attributable to their treatment, which they had experienced in the previous 3 months. With respect to adherence, patients were asked if they had ever skipped injections, whether they had skipped injections in the previous 3 months and, if so, how many, whether they had ever stopped their treatment and, if so, for how long. Reasons for skipping and stopping were also investigated. The impact of treatment on quality of life was measured using a seven-item scale. The items related to physical activity, morale/mood, social life or leisure pursuits, professional activity, relationships/sex life, family and emotional life, and overall quality of life. Each item was graded on an 11-point Likert scale ( 0 , very considerable negative impact; 10, no impact).

\section{Psychometric evaluation of quality of life score}

Because the quality of life scale had not been previously validated, we performed a preliminary evaluation of its psychometric properties. This included determination of the 
Cronbach's $\alpha$ coefficient of internal consistency, pairwise evaluation of correlation between the seven items of the scale, and factorial analysis using principal component analysis.

\section{Statistical analysis}

Univariate statistics were used to describe the results of the survey, using the mean and standard deviation for continuous variables and numbers and percentages for categorical ones. Treatment groups were compared using the Student's $t$-test for continuous variables and Pearson's $\chi^{2}$ test for categorical variables. The association between adherence and four relevant study variables selected a priori by the scientific committee (age, information about disease, information about treatment, and immunomodulatory drugs prescribed) was also evaluated, as well as on-treatment relapse rate. For this analysis, non adherence was defined as missing at least one injection over the previous 3 months.

\section{Ethical considerations}

The survey protocol was submitted for evaluation to the national ethics advisory board. They considered that participation of patients in the study would not affect their medical care, and therefore that it was not necessary to obtain ethics committee approval. Patients were provided with information on the goals and methods of the study and verbal consent was obtained from each patient. The study protocol was submitted to the Commission Nationale de l'Informatique et des Libertés, responsible for overseeing data privacy in France.

\section{Results}

Of the 175 neurologists who had agreed to take part, 47\% were practicing in a hospital setting only, $28 \%$ were in community practice, and $25 \%$ worked in both settings. Of these, 84 neurologists (48.0\%) recruited at least one patient who returned their questionnaire. A total of 202 patients completed and returned the questionnaire, and these comprised the study population. The demographic and clinical features of the study population are summarized in Table 1 according to the immunomodulatory treatment prescribed. Three quarters of the patients were women and the mean age of the sample was 41 years. The mean duration of disease was $8.0 \pm 7.0$ years, and 42 patients (20.8\%) had been diagnosed less than 3 years previously. During the previous 24 months, 32\% of the patients had not experienced an attack, whereas $61 \%$ had experienced 1-3 attacks. The median EDSS disability score at the last evaluation was 2.2 overall, with no significant differences between immunomodulatory treatment groups. For most patients, the EDSS was determined at the study visit itself; the mean interval between the last EDSS evaluation and study inclusion was 2.8 months.

\section{Immunomodulatory treatments}

Most of the patients were being treated with an interferon (principally interferon- $\beta$ 1a by intramuscular injection; 93 patients, $46 \%$ ), while 36 patients $(17.8 \%)$ had been prescribed glatiramer acetate (Table 1). The majority of patients $(n=156 ; 77.2 \%)$ were taking their first-line therapy, although the proportion of patients currently treated with glatiramer acetate as a second-line therapy (18 patients; $50.0 \%$ ) was higher than the corresponding proportion for patients treated with an interferon- $\beta$ preparation (28 patients; $83.0 \%$ ). Only three patients currently treated with an interferon had previously received glatiramer acetate. The mean duration of treatment ranged from 1.1 years for glatiramer acetate to 4.0 years for interferon- $\beta$ 1a by intramuscular injection.

With respect to the choice of treatment, the patients followed the advice of their neurologist in the majority of cases (112 patients; $55.4 \%)$. In 81 cases $(40.1 \%)$, the neurologist proposed a choice of treatments to the patient, whereas nine patients $(4.5 \%)$ requested a specific medication from their neurologist. For the 90 patients who were involved in the choice of treatment, the primary consideration was most frequently efficacy (38 patients; $42.2 \%$ ), followed by injection frequency (25 patients; 27.8\%), anticipated side effects (14 patients; $15.6 \%$ ), and whether they could get help with their injections (11 patients; 5.4\%). Somewhat over half of the patients were performing their own injections $(\mathrm{n}=114 ; 56.4 \%)$, whereas $55(27.2 \%)$ were receiving their injections from a family member or friend and 27 (13.4\%) from a nurse.

The current immunomodulatory treatment had been administered for a mean period of $3.0 \pm 2.0$ years, with 47 patients $(23.3 \%)$ having been prescribed the same treatment for 5 years or more and $35(17.3 \%)$ for less than one year. Sixty-one patients $(30.2 \%)$ had already switched between different immunomodulatory treatments. The switch was initiated by the neurologist in 45 cases and requested by the patient in 12 cases. The main reasons reported for the switch was poor tolerability (33 patients) and perceived lack of efficacy (28 patients). Eight patients reported having switched because they wanted to try a new treatment and six patients because they wanted to use a more convenient treatment. The adverse events most often reported as having led to a change in treatment were "flu-like" symptoms 
Table I Demographic and clinical features of the survey sample

\begin{tabular}{|c|c|c|c|c|c|}
\hline & $\begin{array}{l}\text { Interferon- } \beta \text { I a IM } \\
(n=93)\end{array}$ & $\begin{array}{l}\text { Interferon- } \beta \text { Ia SC } \\
(n=32)\end{array}$ & $\begin{array}{l}\text { Interferon- } \beta \text { Ib SC } \\
(n=4 I)\end{array}$ & $\begin{array}{l}\text { Glatiramer acetate } \\
(n=36)\end{array}$ & $\begin{array}{l}\text { Total } \\
(n=202)\end{array}$ \\
\hline \multicolumn{6}{|l|}{ Gender } \\
\hline Men & $18(19.4 \%)$ & II (34.4\%) & $9(22.0 \%)$ & $12(33.3 \%)$ & $50(24.8 \%)$ \\
\hline Women & 75 (80.6\%) & $21(65.6 \%)$ & $32(78.0 \%)$ & $24(66.7 \%)$ & $152(75.2 \%)$ \\
\hline \multicolumn{6}{|l|}{ Age (years) } \\
\hline Mean \pm SD & $41.8 \pm 10.3$ & $40.5 \pm 9.9$ & $40.0 \pm 10.0$ & $39.1 \pm 8.6$ & $40.7 \pm 9.9$ \\
\hline$<25$ years & $4(4.3 \%)$ & I (3.1\%) & $2(4.9 \%)$ & I (2.8\%) & $8(4.0 \%)$ \\
\hline $25-34$ years & $18(19.4 \%)$ & $8(25.0 \%)$ & $13(31.7 \%)$ & $12(33.3 \%)$ & $5 \mathrm{I}(25.2 \%)$ \\
\hline $35-44$ years & $31(33.3 \%)$ & $13(40.6 \%)$ & $13(3 \mid .7 \%)$ & $10(27.8 \%)$ & $67(33.2 \%)$ \\
\hline $45-54$ years & $30(32.3 \%)$ & $6(18.8 \%)$ & $10(24.4 \%)$ & $12(33.3 \%)$ & $58(28.7 \%)$ \\
\hline $55-64$ years & 7 (7.5\%) & $4(12.5 \%)$ & $3(7.3 \%)$ & $\mathrm{I}(2.8 \%)$ & $15(7.4 \%)$ \\
\hline$\geq 65$ years & $3(3.2 \%)$ & - & - & - & $3(1.5 \%)$ \\
\hline Marital status & $\mathrm{n}=93$ & $\mathrm{n}=32$ & $\mathrm{n}=40$ & $\mathrm{n}=36$ & $\mathrm{n}=201$ \\
\hline Single & 19 (20.4\%) & $5(15.6 \%)$ & $8(20.0 \%)$ & $8(22.2 \%)$ & 40 (19.9\%) \\
\hline Married & $61(65.6 \%)$ & $26(81.3 \%)$ & $31(77.5 \%)$ & $2 \mathrm{I}(58.3 \%)$ & 139 (69.2\%) \\
\hline Widowed & $\mathrm{I}(\mathrm{I} . \mathrm{l} \%)$ & - & - & $\mathrm{I}(2.8 \%)$ & $2(1.0 \%)$ \\
\hline Divorced or separated & $12(12.9 \%)$ & I (3.I\%) & I (2.5\%) & $6(16.7 \%)$ & $20(10.0 \%)$ \\
\hline Number of children & $\mathrm{n}=88$ & $\mathrm{n}=26$ & $\mathrm{n}=39$ & $\mathrm{n}=35$ & $\mathrm{n}=188$ \\
\hline 0 & $20(22.7 \%)$ & $5(19.2 \%)$ & 14 (35.9\%) & $12(34.3 \%)$ & $5 \mathrm{I}(27.1 \%)$ \\
\hline 1 & 25 (28.4\%) & $2(7.7 \%)$ & $9(23.1 \%)$ & 8 (22.9\%) & $44(23.4 \%)$ \\
\hline 2 & $29(33.0 \%)$ & $13(50.0 \%)$ & $13(33.3 \%)$ & $10(28.6 \%)$ & $65(34.6 \%)$ \\
\hline$\geq 3$ & 14 (I5.9\%) & $6(23.1 \%)$ & $3(7.7 \%)$ & $5(14.3 \%)$ & $28(14.9 \%)$ \\
\hline Employment status & $\mathrm{n}=91$ & $\mathrm{n}=32$ & $\mathrm{n}=39$ & $\mathrm{n}=34$ & $\mathrm{n}=196$ \\
\hline Employed & 71 (78.0\%) & $20(62.5 \%)$ & $32(82.0 \%)$ & $26(76.5 \%)$ & 149 (76.0\%) \\
\hline Not in employment & $20(22.0 \%)$ & $12(37.5 \%)$ & $7(18.0 \%)$ & $8(23.5 \%)$ & 47 (24.0\%) \\
\hline \multicolumn{6}{|l|}{ Disease duration } \\
\hline Mean \pm SD & $9.0 \pm 7.0$ & $8.0 \pm 6.1$ & $7.1 \pm 8.1$ & $6.1 \pm 5.1$ & $8.0 \pm 7.0$ \\
\hline \multicolumn{6}{|l|}{ Treatment duration (years) } \\
\hline Mean \pm SD & $4.0 \pm 2.1$ & $3.0 \pm 2.0$ & $2.1 \pm 1.1$ & $1.1 \pm 1.0$ & $3.0 \pm 2.0$ \\
\hline Median & 3.9 & 3.0 & 2.5 & I.I & 2.8 \\
\hline Relapses in previous 24 months & $\mathrm{n}=93$ & $\mathrm{n}=32$ & $\mathrm{n}=40$ & $\mathrm{n}=36$ & $\mathrm{n}=20 \mathrm{I}$ \\
\hline 0 & 37 (39.8\%) & $12(37.5 \%)$ & $10(25.0 \%)$ & $5(13.9 \%)$ & $64(31.8 \%)$ \\
\hline 1 & $23(24.7 \%)$ & $9(28.1 \%)$ & $16(40.0 \%)$ & $16(44.4 \%)$ & $64(31.8 \%)$ \\
\hline 2 or 3 & $28(30.1 \%)$ & $10(31.3 \%)$ & $12(30.0 \%)$ & $9(25.0 \%)$ & 59 (29.4\%) \\
\hline 4 or 5 & $3(3.2 \%)$ & $\mathrm{I}(3.1 \%)$ & $2(5.0 \%)$ & $5(13.9 \%)$ & $\mathrm{II}(5.5 \%)$ \\
\hline$>5$ & $2(2.2 \%)$ & - & - & I (2.8\%) & $3(1.5 \%)$ \\
\hline EDSS score at inclusion (mean \pm SD) & $2.0 \pm 1.4$ & $2.5 \pm 1.7$ & $2.3 \pm 1.5$ & $2.2 \pm 1.2$ & $2.2 \pm 1.5$ \\
\hline EDSS $<4$ & 78 (83.9\%) & $20(62.5 \%)$ & $33(80.5 \%)$ & $32(88.9 \%)$ & $163(80.7 \%)$ \\
\hline EDSS $\geq 4$ & $15(16.1 \%)$ & $12(37.5 \%)$ & $8(19.5 \%)$ & 4 (11.1\%) & 39 (19.3\%) \\
\hline Nonadherence rate & $18(19.4 \%)$ & $9(28.1 \%)$ & 13 (31.7\%) & $13(36.1 \%)$ & 53 \\
\hline
\end{tabular}

Abbreviations: EDSS, Expanded Disability Status Scale; IM, intramuscular; SC, subcutaneous; SD, standard deviation.

(19 patients) and injection site reactions (seven patients). Of the 61 patients who had switched, 41 were better satisfied with their new treatment, whereas four were less satisfied.

With respect to treatment adherence, 85 patients $(42.1 \%)$ reported missing their injections from time to time and $53(26.2 \%)$ had missed at least one injection in the previous 3 months. The number of injections missed over this period was 1-3 for 44 of these patients, and only nine patients had missed more than three injections. The number of patients missing at least one injection over the past 3 months was higher in younger patients and in patients who considered themselves not well informed about their disease (Table 2). No such difference in this variable was observed between the different treatments, although a trend towards a lower proportion of patients missing their injections was observed for those using interferon- $\beta$ 1a. In addition, no association was observed between nonadherence and relapses in the previous 2 years.

In addition, 36 patients (17.8\%) reported that they had stopped their treatment for a while. Fourteen patients had stopped for less than a week, whereas ten had stopped for over one month. Only a minority of patients who skipped 
Table 2 Adherence to treatment

\begin{tabular}{|c|c|c|c|}
\hline Variable & $\mathbf{n}$ & Nonadherent & $\boldsymbol{P}$ \\
\hline \multicolumn{4}{|l|}{ Age group } \\
\hline$<35$ years & 59 & $21(35.6 \%)$ & \multirow[t]{3}{*}{0.047} \\
\hline $35-44$ years & 67 & $19(18.6 \%)$ & \\
\hline$\geq 45$ years & 76 & $13(33.0 \%)$ & \\
\hline \multicolumn{4}{|c|}{ Information about disease } \\
\hline Well informed & 86 & $16(18.6 \%)$ & \multirow[t]{2}{*}{0.035} \\
\hline Not well informed & 112 & $37(33.0 \%)$ & \\
\hline \multicolumn{4}{|c|}{ Information about treatment } \\
\hline Well informed & 70 & 15 (2I.4\%) & \multirow[t]{2}{*}{0.129} \\
\hline Not well informed & 120 & $38(31.7 \%)$ & \\
\hline \multicolumn{4}{|l|}{ Treatment } \\
\hline Interferon- $\beta$ Ia IM & 93 & 18 (19.4\%) & \multirow[t]{4}{*}{0.189} \\
\hline Interferon- $\beta$ Ia SC & 32 & $9(28.1 \%)$ & \\
\hline Interferon- $\beta$ Ib SC & 41 & 13 (31.7\%) & \\
\hline Glatiramer acetate & 36 & $13(36.1 \%)$ & \\
\hline \multicolumn{4}{|c|}{ Relapses in previous 24 months } \\
\hline None & 64 & $16(25.0 \%)$ & \multirow[t]{5}{*}{0.473} \\
\hline One & 64 & $19(29.7 \%)$ & \\
\hline Two or three & 59 & 14 (23.7\%) & \\
\hline Four or five & II & $2(18.2 \%)$ & \\
\hline More than five & 3 & $2(66.7 \%)$ & \\
\hline
\end{tabular}

Notes: Data are presented as the number (\%) of nonadherent patients, defined as those missing at least one injection over the past 3 months; probabilities are calculated with the $\chi^{2}$ test.

Abbreviations: SC, subcutaneous; IM, intramuscular.

injections ( 35 of 85 patients) or interrupted treatment (nine of 36) reported discussing this with their neurologist usually or sometimes.

The reasons most frequently given for skipping or stopping treatment were forgetfulness (38.7\% of 93 patients stopping or skipping) and weariness with injections (28.0\%). Side effects were mentioned by $14.0 \%$ of these patients. Other reasons given included travel $(21.5 \%)$, holidays $(7.5 \%)$, neurologist advice (10.8\%), to help not thinking about being ill (8.6\%), pregnancy $(3.2 \%)$, and surgery (2.2\%). Perceived lack of efficacy does not seem to have been a reason for nonadherence.

\section{Patient information}

Patients were asked whether they considered themselves well informed about their disease and its treatment. Eighty-six patients (42.6\%) reported considering that they had been well informed about their disease, and $70(34.7 \%)$ reported that they had been well informed about their treatment (Table 3). The source of information most frequently cited was the neurologist, followed by the Internet, general practitioners, patient groups, and health care networks (Table 3). Nearly half of the patients expressed a desire for more contact with their neurologist and general practitioner (Table 3). There was much less demand for closer contact with a nurse, a pharmacist, or other health care professionals.
Table 3 Patient information

\begin{tabular}{ll}
\hline I am well informed about my disease & \\
Totally agree & $86(42.6 \%)$ \\
Partly agree & $90(44.6 \%)$ \\
Partly disagree & $18(8.9 \%)$ \\
Totally disagree & $4(2.0 \%)$ \\
No opinion & $4(2.0 \%)$ \\
I am well informed about my treatment & \\
Totally agree & $70(34.7 \%)$ \\
Partly agree & $81(40.1 \%)$ \\
Partly disagree & $29(14.4 \%)$ \\
Totally disagree & $10(5.0 \%)$ \\
No opinion & $12(5.9 \%)$ \\
Source of information & \\
Neurologist & $182(90.1 \%)$ \\
Internet & $89(44.1 \%)$ \\
General practitioner & $77(38.1 \%)$ \\
Patient association & $40(19.8 \%)$ \\
Care network & $20(9.9 \%)$ \\
Pharmacist & $10(5.0 \%)$ \\
Other & $12(5.9 \%)$ \\
Desire for more contact & \\
With neurologist & $98(48.5 \%)$ \\
With general practitioner & $81(40.1 \%)$ \\
With nurse & $27(13.4 \%)$ \\
With pharmacist & $19(9.4 \%)$ \\
With other health care professionals & $8(4.0 \%)$ \\
\hline
\end{tabular}

\section{Social support}

Most patients reported that they had informed their spouse/partner $(\mathrm{n}=166 ; 82.2 \%)$, other family members $(\mathrm{n}=196 ; 97.0 \%)$, and friends $(\mathrm{n}=160 ; 79.2 \%)$ that they had multiple sclerosis. Of the 149 patients who were working, $89(59.7 \%)$ said that they had told their colleagues about their disease. None of the patients reported that nobody knew about their multiple sclerosis. Some degree of involvement of family and friends in managing multiple sclerosis was recognized by 172 patients $(85.1 \%$ ), the level of involvement being reported as considerable by 68 patients, moderate by 75 patients, and low by 29 patients.

\section{Perception of treatment}

A large majority of patients $(n=176 ; 87.1 \%)$ stated that they intended continuing their current treatment until a more effective new treatment became available. Only nine patients $(4.5 \%)$ claimed to be considering stopping their treatment.

Patients were asked how they thought that their current treatment would help them and what had changed since starting treatment (Table 4). Around one half (100 patients; $49.5 \%$ ) totally agreed that their current treatment would help reduce relapses and $35.6 \%$ agreed that it would slow disease progression. Around one third totally agreed that they lived 
Table 4 Treatment perceptions

\begin{tabular}{ll}
\hline Current treatment helps reduce relapse frequency & \\
Totally agree & $100(49.5 \%)$ \\
Partly agree & $80(39.6 \%)$ \\
Partly disagree & $12(5.9 \%)$ \\
Totally disagree & $4(2.0 \%)$ \\
No opinion & $6(3.0 \%)$ \\
Current treatment helps slow disease progression & \\
Totally agree & $72(35.6 \%)$ \\
Partly agree & $100(49.5 \%)$ \\
Partly disagree & $18(8.9 \%)$ \\
Totally disagree & $3(1.5 \%)$ \\
No opinion & $9(4.5 \%)$ \\
I live better with MS since starting treatment & \\
Totally agree & $67(33.2 \%)$ \\
Partly agree & $80(39.6 \%)$ \\
Partly disagree & $29(14.4 \%)$ \\
Totally disagree & $19(9.4 \%)$ \\
No opinion & $7(3.5 \%)$ \\
I am more optimistic about my MS since starting treatment & \\
Completely agree & $56(27.7 \%)$ \\
Partly agree & $91(45.0 \%)$ \\
Partly disagree & $34(16.8 \%)$ \\
Completely disagree & $15(7.4 \%)$ \\
No opinion & $6(3.0 \%)$ \\
\hline
\end{tabular}

Abbreviation: MS, multiple sclerosis.

better with their disease and felt more optimistic about it since starting therapy. Less than $10 \%$ totally disagreed with any of these statements.

Only ten patients reported experiencing no side effects attributable to treatment in the preceding months, and most reported multiple side effects (mean $5.0 \pm 3.0$ ).
The most frequently reported were muscle pain (124 patients; 61.4\%), headache (120 patients; $59.4 \%$ ), post-injection fatigue (113 patients; $55.9 \%$ ), and flu-like states (112 patients; 55.0\%). Because the adverse event profiles of interferon- $\beta$ preparations and glatiramer acetate are different, a separate analysis was made for each treatment class (Figure 1). The proportion of patients reporting post-injection fatigue and flu-like states was significantly higher $(P<0.001)$ in patients using an interferon- $\beta$ than in those using glatiramer acetate. In contrast, injection site reactions were more frequently reported by patients using glatiramer acetate $(P=0.001)$. No obvious differences were observed in reported side effects between patients using different interferon- $\beta$ preparations (data not shown). The patients most frequently discussed these side effects with their neurologist ( $\mathrm{n}=190 ; 94.1 \%$ of cases), either spontaneously or when asked. They also discussed them with their general practitioner $(n=125 ; 61.9 \%)$ or with nurses $(n=62 ; 30.7 \%)$.

Overall, 153 patients $(75.7 \%)$ said that they had taken medication to relieve the side effects of their treatment. This was reported less frequently $(P<0.001)$ by patients taking glatiramer acetate $(41.7 \%)$ than by those taking interferons (83.1\%). Of these medications, analgesics were the most frequently consumed class of drug. Again, patients treated with glatiramer acetate reported consuming analgesics less frequently than did those receiving an interferon $(27.8 \%$ versus $78.3 \% ; P<0.001)$. Use of antidepressants was reported by

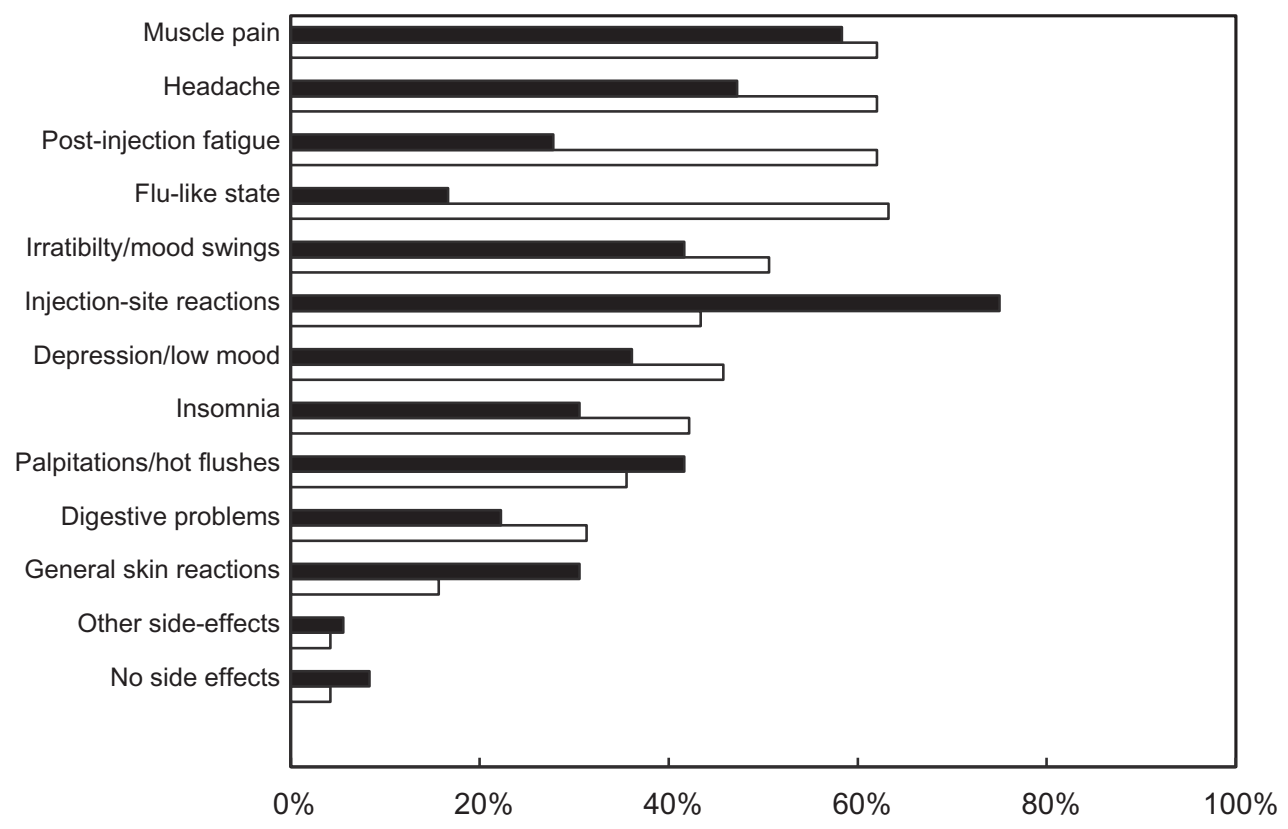

Figure I Patient-reported side effects.

Notes: Open bars, interferon- $\beta(n=166)$; filled bars, glatiramer acetate $(n=36)$. 
37 patients (18.3\%) and sedative use by 26 (12.9\%), with no difference between the treatment groups.

The majority of patients $(n=169 ; 83.7 \%)$ reported not being bothered by having to undergo regular blood tests for monitoring of their treatment, with only 18 patients (8.9\%) claiming to be very or quite bothered by this.

\section{Impact of disease}

Patients were asked how they considered that their disease affected their life. Around two thirds of the patients $(n=136)$ reported that they tried to live normally and forget their multiple sclerosis, whereas 21 patients $(10.4 \%)$ considered that it was impossible for them to have a normal life (Figure 2). In order to assess impact of the treatment on quality of life, seven dimensions were evaluated on a scale ranging from 0 (very considerable negative impact) to 10 (no impact). The median overall quality of life score was 6 (interquartile range 4-9; mean $6.05 \pm 3.03$ ). The item most affected was physical activity (median score 6 [3-10]). Patients treated with glatiramer acetate reported that their quality of life was somewhat less affected by treatment than patients treated with interferon- $\beta$ preparations (Table 5 ), with a median overall quality of life score of 7 (5-10) versus 5 (4-9). A similar trend could be observed for most of the individual items of the scale (Table 5).

Eighty patients (39.6\%) reported having to give up their regular activities due to their illness (Figure 3), and for more than ten days in 34 patients (16.8\%). Among the 149 patients who were working, 46 (30.9\%) had taken at least one day off work during the three months preceding the survey due to their illness, and $24(16.1 \%)$ had taken more than ten days off (Figure 4). Forty-one patients using interferon- $\beta$ (33.3\%) and five patients using glatiramer acetate (19.2\%) reported taking at least one day off work.

\section{Psychometric properties of quality of life scale}

Internal consistency of the quality of life scale was high, with a Cronbach's $\alpha$ coefficient of 0.935 . Pairwise correlations of scores on each item of the scale were all significant $(P>0.05)$ and individual correlation coefficients ranged from 0.543 between "professional activities" and "relationships/ sex life" to 0.847 between "physical activity" and "social life/leisure" (Table 6). Correlation coefficients $>0.60$ are considered good and those $>0.80$ very good. Factorial analysis showed the scale to be unidimensional, with $94 \%$ of the explained variance in the data being accounted for by a single dimension with an Eigenvalue of 4.76. This was the only dimension to have an Eigenvalue $>1$, which is the generally accepted threshold for relevance. Correlations between individual item scores and the factor score were all $>0.75$, indicating a good fit to the data.

\section{Discussion}

This study surveyed 202 patients with multiple sclerosis treated with an immunomodulatory agent for an average of 3 years. The most widely used immunomodulatory treatment was interferon- $\beta$ 1a intramuscularly. The distribution of treatments used was consistent with the known market share of these medications at the time of the survey.

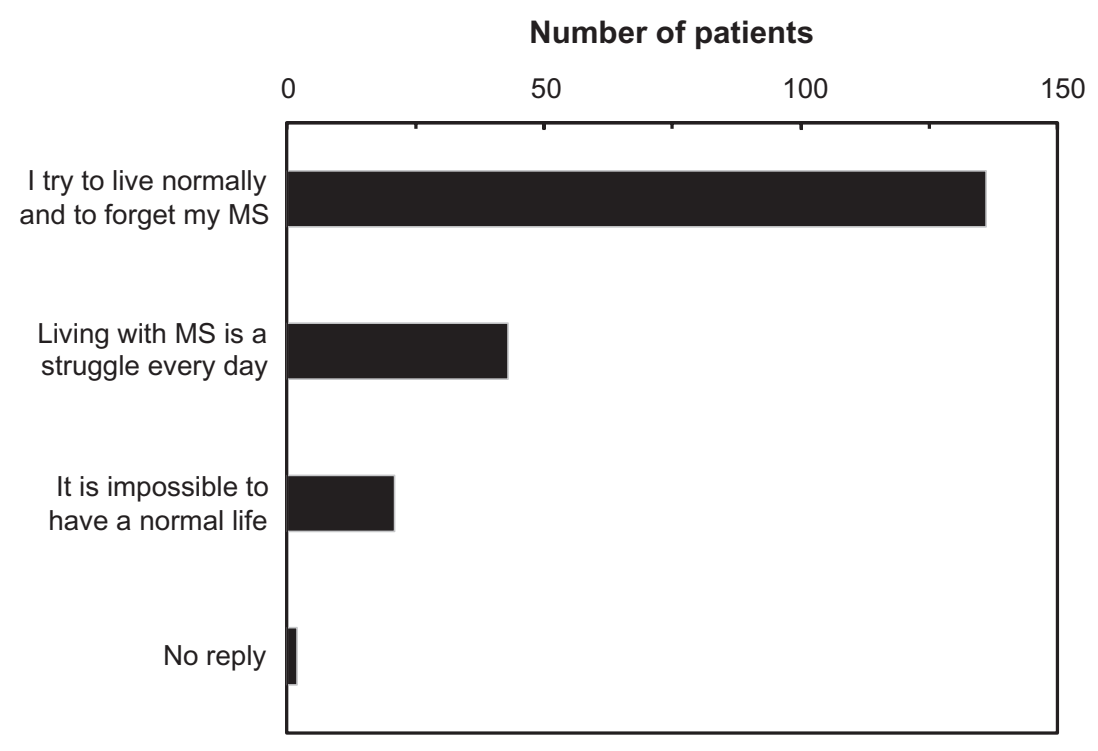

Figure 2 Impact of disease. 
Table 5 Impact of treatment on quality of life according to treatment

\begin{tabular}{llll}
\hline & All interferon- $\beta$ & $\begin{array}{l}\text { Glatiramer } \\
\text { acetate }\end{array}$ & Total \\
\hline Physical activity & $6(3-9)$ & $8.5(2.75-10)$ & $6(3-10)$ \\
Morale/mood & $6(3.75-9)$ & $7(6-10)$ & $7(4-9)$ \\
Social life/leisure & $7(3-9)$ & $8(3.75-10)$ & $7(3-9)$ \\
Professional activities & $7(3-10)$ & $9.5(4-10)$ & $8(3-10)$ \\
Relationships/sex life & $8(4.75-10)$ & $7.5(4-10)$ & $8(4-10)$ \\
Family/emotional life & $8(4-10)$ & $8(5-10)$ & $8(5-10)$ \\
Overall quality of life & $5(4-9)$ & $7(5-10)$ & $6(4-9)$ \\
\hline
\end{tabular}

Over half of the patients reported that they had followed their neurologist's advice in the choice of treatment and only $45 \%$ claimed to have had any input in the treatment decision. This suggests that the extent of patient empowerment in everyday clinical practice in France, at least at the time of the study, was relatively low, in spite of recognition that this is important. When patients did have a say in the choice of treatment, efficacy was the principal criterion of choice.

Adherence was assessed on the basis of patient selfreport. In the sample, $26.2 \%$ of patients reported that they had skipped medication at least once in the previous 3 months, although for most of these no more than three doses had been missed. This is likely to be an underestimate due to the source of information, because patients may be unwilling to admit to themselves or to others that they are noncompliant, as indicated by the observation that most did not discuss the issue with their physician. More objective methods of collecting data on adherence, such as prescription claims surveys, would be useful to address this point.
For example, the medication possession ratio represents the number of doses dispensed in relation to the dispensing period over a given time period. ${ }^{16}$ The medication possession ratio has been evaluated in the PRISMS (Prevention of Relapses and Disability by Interferon beta-1a Subcutaneously in Multiple Sclerosis) trial of interferon- $\beta$ 1a subcutaneously, a pivotal clinical trial where adherence may be expected to be high. In this trial, the medication possession ratio was $78 \%$, suggesting that patients were skipping one in four of their scheduled doses. ${ }^{17}$ Two recent prescription claims studies from the US also reported a medication possession ratio of around 0.75 for different immunomodulatory treatments used in everyday practice. ${ }^{18,19}$ A prospective study from Australia reported that $73 \%$ of patients missed doses over a mean follow-up period of 2.4 years. ${ }^{20}$

Two factors were identified as being important determinants of adherence, ie, patient age and degree of information about disease. The best informed and oldest patients were the most compliant. The survey also showed that half of the patients did not consider themselves well informed. A similar but not significant trend was also observed for better adherence in patients who considered themselves well informed about their treatment. The recent Global Adherence Project ${ }^{21}$ used multivariate logistic analysis to identify factors independently related to adherence with immunomodulatory therapy in patients with multiple sclerosis. This study reported superior adherence in women compared with men, in patients earlier on in their disease course, and in patients who had more support from families and neurologists. The relationship between these factors and adherence was not evaluated in the present study.

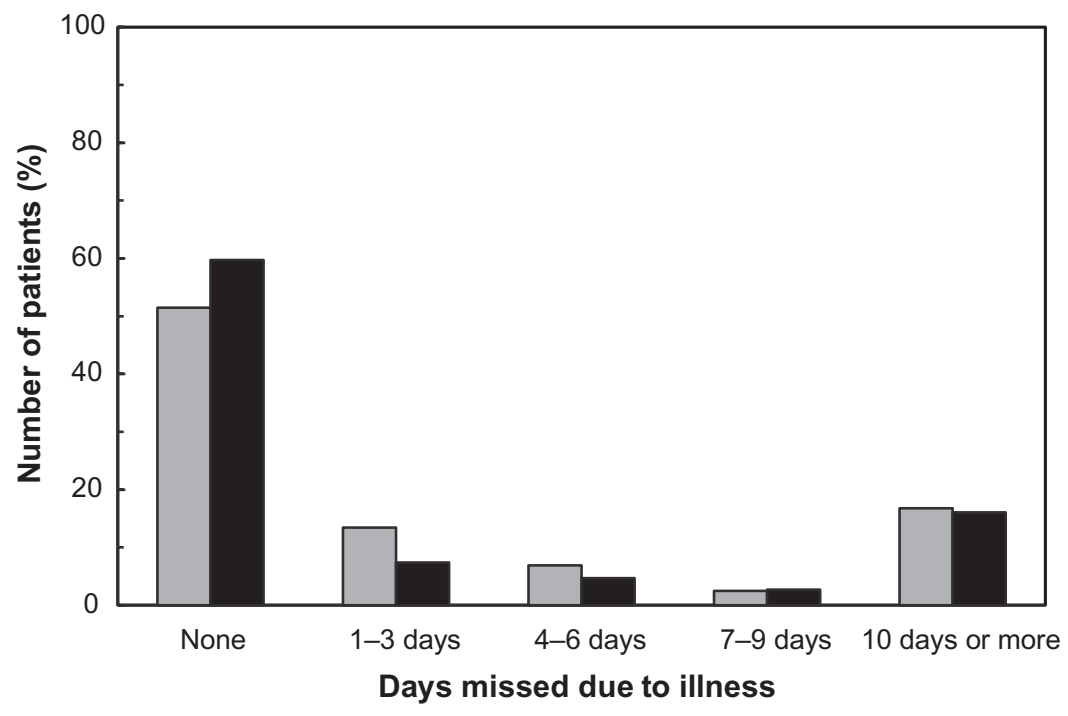

Figure 3 Interference with activities of daily living. Data are expressed as days missed due to multiple sclerosis in the previous 3 months. Notes: Gray columns, all patients $(n=202)$, professional activities or normal daily activities; black columns, patients in employment $(n=149)$, professional activities. 
We failed to observe a significant difference in self-reported adherence rates between the four immunomodulatory treatments. Other studies have reported superior adherence to intramuscular interferon- $\beta$ 1a than to subcutaneously administered treatments, ${ }^{19,21,22}$ and our study shows a trend in this direction. It is possible that the relatively low patient numbers limit the statistical power to demonstrate intergroup differences. Nevertheless, it is important to note that the consequences of missing a single dose of the four available immunomodulatory treatments is not the same, because different treatments are administered at different frequencies. Consequently, missing one injection of weekly intramuscular interferon- $\beta$ 1a in a month corresponds to missing $25 \%$ of the scheduled dose, equivalent to missing seven injections of glatiramer acetate. For the 44 patients who reported missing between one and three injections in the previous 3 months, this corresponds to $8.3 \%-25.0 \%$ of the total planned intramuscular dose of interferon- $\beta$ 1a, but only $0.1 \%-0.3 \%$ of the total planned dose of glatiramer acetate.

We also observed that $18 \%$ of patients interrupted their treatment for at least a week. This is a considerably lower rate than that previously reported in a large Canadian cohort, in which $33 \%$ of 846 patients treated with an interferon- $\beta$ stopped treatment for at least one month. ${ }^{13}$ This difference may be due to under-reporting or to the fact that all patients in the survey had been on treatment for at least 3 months at the time of the study. Another important aspect of adherence, namely treatment persistence, cannot be addressed in this study for this same reason. However, much information has already been published on persistence with immunomodulatory treatment for multiple sclerosis, showing this to be poor. ${ }^{9-13}$

Amongst the reasons for non adherence with treatment, forgetfulness was the most frequently cited, together with injection fatigue and side effects. These findings are consistent with those of the Global Adherence Project on patient adherence. ${ }^{21}$ Even though efficacy was the primary criterion in selecting the treatment for multiple sclerosis, poor efficacy was not frequently cited as a reason for non adherence in our study, although it appears from other studies to be a major reason for treatment discontinuation. ${ }^{13,23}$ In this study, most of the patients thought that the treatment that they were taking reduced the frequency of relapses and slowed progression of the disease.

Given that side effects were cited as a reason for non adherence and that these differ between available immunomodulatory treatments, patient perceptions of side effects are also of relevance. Less than $5 \%$ of patients reported that their treatments had no side effects. Injection site reactions were reported more frequently with glatiramer acetate and influenza-like syndromes and post-injection fatigue more frequently with interferon- $\beta$, consistent with experience from clinical trials. Use of symptomatic medication for management of side effects, notably analgesics, was reported significantly more frequently in patients using interferon- $\beta$ compared with those using glatiramer acetate.

Overall reported quality of life was somewhat less impaired in patients using glatiramer acetate than in those treated by interferon- $\beta$. This may reflect the lower tendency of glatiramer acetate to aggravate fatigue compared with interferon- $\beta$, as has been reported previously. ${ }^{3}$ The difference is unlikely to be accounted for by prescription of interferon- $\beta$ to patients with more severe disease, given that EDSS scores were comparable across treatment groups. However, these findings should be interpreted with caution, because the treatment duration and previous history differed between the patients receiving interferon- $\beta$ and those receiving glatiramer acetate.

The study also collected information on how well the patients considered themselves to be informed about their disease and its treatment. Fewer than half of the patients said that they were well informed about their disease. This is consistent with the desire expressed by half of the patients for more contact with their neurologist and their general practitioner. Considering that patient information seems to be important for optimizing adherence, it is important for neurologists to involve the patient as soon as treatment is started, and to give more adequate information about the

Table 6 Correlation matrix of scores on seven items of the quality of life questionnaire

\begin{tabular}{|c|c|c|c|c|c|c|c|}
\hline Variable & $\begin{array}{l}\text { Family/ } \\
\text { emotional life }\end{array}$ & $\begin{array}{l}\text { Moralel } \\
\text { mood }\end{array}$ & $\begin{array}{l}\text { Social life/ } \\
\text { leisure }\end{array}$ & $\begin{array}{l}\text { Physical } \\
\text { activity }\end{array}$ & $\begin{array}{l}\text { Relationships/ } \\
\text { sex life }\end{array}$ & $\begin{array}{l}\text { 6-professional } \\
\text { activities }\end{array}$ & $\begin{array}{l}\text { 7-overall } \\
\text { quality of life }\end{array}$ \\
\hline Family/emotional life & I & 0.757 & 0.695 & 0.582 & 0.653 & 0.565 & 0.804 \\
\hline Morale/mood & 0.757 & I & 0.633 & 0.561 & 0.604 & 0.577 & 0.781 \\
\hline Social life/leisure & 0.695 & 0.633 & I & 0.847 & 0.597 & 0.653 & 0.820 \\
\hline Physical activity & 0.582 & 0.561 & 0.847 & I & 0.585 & 0.674 & 0.751 \\
\hline Relationships/sex life & 0.653 & 0.604 & 0.597 & 0.585 & 1 & 0.543 & 0.720 \\
\hline Professional activities & 0.565 & 0.577 & 0.653 & 0.674 & 0.543 & I & 0.746 \\
\hline Overall quality of life & 0.804 & 0.781 & 0.820 & 0.751 & 0.720 & 0.746 & $\mathrm{I}$ \\
\hline
\end{tabular}


disease and its treatment, in particular about the potential impact on quality of life, which differs from one treatment to another. By taking into consideration patient perceptions of treatment in terms of efficacy, safety, and impact on quality of life, as well as involving patients more in sharing treatment decisions, the clinician can take a more personal interest in the individual patient. As a result, the patient may become more actively involved in managing the disease, and thus facilitate the chances of achieving the goal of optimal adherence with treatment. ${ }^{15}$

This survey collected data directly from patients using a questionnaire completed at home, and sent directly to the data analysis center. This methodological approach has both strengths and weaknesses. On the positive side, this approach should improve the spontaneity of patient replies compared with collecting the data through the physician. This approach also circumvents the mismatch between physician and patient perceptions of the disease and its impact. ${ }^{24}$ On the negative side, reporting bias cannot be excluded. Adherence rates are likely to be underestimated, and there is no way of ascertaining the incidence of side effects and duration of sick leave. The response rate for neurologists is at first sight rather low $(12.5 \%)$, but this is to be expected, given that around two thirds of practicing neurologists in France do not regularly manage patients with multiple sclerosis. Taking the 400 neurologists in the French Multiple Sclerosis Observatory, who see almost all multiple sclerosis patients in France as the denominator, the response rate was around $45 \%$. Nonetheless, it is possible that incomplete participation of neurologists introduces some selection bias. In addition, no information is available on patients who refused to participate and, again, this is an important source of potential selection bias.

It should also be noted that the survey was carried out before natalizumab became available for the treatment of multiple sclerosis in France. Seven of eight patients said that they would stay on their current treatment until a potential alternative would be available. The introduction of natalizumab and of the emerging oral therapies may be expected to influence patient perceptions and expectations of their treatments. The data collected in the present study will serve as a useful benchmark to measure the change in treatment perceptions as therapeutic opportunities evolve.

In conclusion, the more our patients are informed about their disease and its treatment, the higher the level of adherence that can be achieved. Neurologists would benefit from developing communication skills to improve patient involvement in the management of their disease.

\section{Acknowledgments}

The study was performed in collaboration with the Association des Neurologues Libéraux de Langue Française.

\section{Disclosures}

The study was initiated and financially supported by Laboratories Sanofi-aventis (Montrouge, France) and Teva (Courbevoie, France). J de Seze serves on scientific advisory boards for and has received honoraria from Biogen Idec, LFB, Merck Serono, Sanofi-aventis, and Bayer Schering Pharma. Dr Borgel and Dr Brudon have received honoraria from Sanofi-aventis and Teva. Editorial support for the preparation of this supplement was provided by Medi Axe (Clamart, France) and SARL Foxymed (Paris, France).

\section{References}

1. Wu N, Minden SL, Hoaglin DC, Hadden L, Frankel D. Quality of life in people with multiple sclerosis: data from the Sonya Slifka Longitudinal Multiple Sclerosis Study. J Health Hum Serv Adm. 2007;30(3):233-267.

2. Ivanova JI, Birnbaum HG, Samuels S, Davis M, Phillips AL, Meletiche D. The cost of disability and medically related absenteeism among employees with multiple sclerosis in the US. Pharmaco Economics. 2009;27(8):681-691.

3. Ziemssen T. Multiple sclerosis beyond EDSS: depression and fatigue. J Neurol Sci. 2009;277 Supp1 1:S37-S41.

4. Jacobs LD, Cookfair DL, Rudick RA, et al. Intramuscular interferon beta-1a for disease progression in relapsing multiple sclerosis. The Multiple Sclerosis Collaborative Research Group (MSCRG). Ann Neurol. 1996;39(3):285-294.

5. Johnson KP, Brooks BR, Cohen JA, et al. Copolymer 1 reduces relapse rate and improves disability in relapsing-remitting multiple sclerosis: results of a phase III multicenter, double-blind placebo-controlled trial. The Copolymer 1 Multiple Sclerosis Study Group. Neurology. 1995;45(7):1268-1276.

6. PRISMS (Prevention of Relapses and Disability by Interferon beta-1a Subcutaneously in Multiple Sclerosis) Study Group. Randomised double-blind placebo-controlled study of interferon beta-1a in relapsing/ remitting multiple sclerosis. Lancet. 1998;352(9139):1498-1504.

7. The IFNB Multiple Sclerosis Study Group and The University of British Columbia MS/MRI Analysis Group. Interferon beta- $1 \mathrm{~b}$ in the treatment of multiple sclerosis: final outcome of the randomized controlled trial. Neurology. 1995;45(7):1277-1285.

8. Ford CC, Johnson KP, Lisak RP, Panitch HS, Shifronis G, Wolinsky JS. A prospective open-label study of glatiramer acetate: over a decade of continuous use in multiple sclerosis patients. Mult Scler. 2006;12(3):309-320.

9. Klauer T, Zettl UK. Compliance, adherence, and the treatment of multiple sclerosis. J Neurol. 2008;255 Suppl 6:87-92.

10. Haas J, Firzlaff M. Twenty-four-month comparison of immunomodulatory treatments - a retrospective open label study in 308 RRMS patients treated with beta interferons or glatiramer acetate (Copaxone). Eur $J$ Neurol. 2005;12(6):425-431.

11. O'Rourke KE, Hutchinson M. Stopping beta-interferon therapy in multiple sclerosis: an analysis of stopping patterns. Mult Scler. 2005;11(1):46-50.

12. Milanese C, La Mantia L, Palumbo R, et al. A post-marketing study on interferon beta $1 \mathrm{~b}$ and $1 \mathrm{a}$ treatment in relapsing-remitting multiple sclerosis: different response in drop-outs and treated patients. J Neurol Neurosurg Psychiatry. 2003;74(12):1689-1692. 
13. Tremlett HL, Oger J. Interrupted therapy: stopping and switching of the beta-interferons prescribed for MS. Neurology. 2003;61(4):551-554.

14. Patti F. Optimizing the benefit of multiple sclerosis therapy: the importance of treatment adherence. Patient Prefer Adherence. 2010;4:1-9.

15. Costello K, Kennedy P, Scanzillo J. Recognizing nonadherence in patients with multiple sclerosis and maintaining treatment adherence in the long term. Medscape J Med. 2008;10(9):225.

16. Cramer JA, Roy A, Burrell A, et al. Medication compliance and persistence: terminology and definitions. Value Health. 2008;11(1): 44-47.

17. Traboulsee A, Uitdehaag BMJ, Kappos L, et al. Measures of treatment adherence as prognostic factors for long-term outcomes in relapsingremitting multiple sclerosis. Mult Scler. 2010;16 Suppl 10:S165.

18. Steinberg SC, Faris RJ, Chang CF, Chan A, Tankersley MA. Impact of adherence to interferons in the treatment of multiple sclerosis: a non-experimental, retrospective, cohort study. Clin Drug Investig. 2010;30(2):89-100.

19. Kleinman NL, Beren IA, Rajagopalan K, Brook RA. Medication adherence with disease-modifying treatments for multiple sclerosis among US employees. J Med Econ. 2010;13(4):633-640.

20. Tremlett H, Van der Mei I, Pittas F, et al. Adherence to the immunomodulatory drugs for multiple sclerosis: contrasting factors affect stopping drug and missing doses. Pharmacoepidemiol Drug Saf. 2008;17(6):565-576.
21. Devonshire V, Lapierre Y, Macdonell R, et al. The Global Adherence Project (GAP): a multicenter observational study on adherence to disease-modifying therapies in patients with relapsing-remitting multiple sclerosis. Eur J Neurol. 2011;18(1):69-77.

22. Arroyo E, Grau C, Ramo C, Parra J, Sanchez-Solino O. Global adherence project to disease-modifying therapies in patients with relapsing multiple sclerosis: 2-year interim results [Estudio global de adherencia a los tratamientos inmunomoduladores en pacientes con esclerosis múltiple remitente recidivante: resultados a 2 años]. Neurologia. 2010;25(7):435-442. [Spanish.]

23. Rio J, Porcel J, Tellez N, et al. Factors related with treatment adherence to interferon beta and glatiramer acetate therapy in multiple sclerosis. Mult Scler. 2005;11(3):306-309.

24. Rothwell PM, McDowell Z, Wong CK, Dorman PJ. Doctors and patients don't agree: cross sectional study of patients' and doctors' perceptions and assessments of disability in multiple sclerosis. $B M J$ 1997;314(7094):1580-1583.
Patient Preference and Adherence

\section{Publish your work in this journal}

Patient Preference and Adherence is an international, peer-reviewed, open access journal focusing on the growing importance of patient preference and adherence throughout the therapeutic continuum. Patient satisfaction, acceptability, quality of life, compliance, persistence and their role in developing new therapeutic modalities and compounds to

\section{Dovepress}

optimize clinical outcomes for existing disease states are major areas of interest. This journal has been accepted for indexing on PubMed Central. The manuscript management system is completely online and includes a very quick and fair peer-review system. Visit http://www.dovepress.com/ testimonials.php to read real quotes from published authors. 